\title{
Exploring the anti-biofilm activity of cinnamic acid derivatives in Candida albicans
}

\author{
Daniela De Vita a,1, Giovanna Simonetti ${ }^{\mathrm{c}, 1}$, Fabiana Pandolfi ${ }^{\mathrm{a}}$, Roberta Costi ${ }^{\mathrm{a}, \mathrm{b}}$, Roberto Di Santo ${ }^{\mathrm{a}, \mathrm{b}}$, \\ Felicia Diodata D'Auria ${ }^{\mathrm{c}}$, Luigi Scipione ${ }^{\mathrm{b}, *}$ \\ ${ }^{a}$ Department of Chimica e Tecnologie del Farmaco, Sapienza University of Rome, P.le A. Moro, 5, I-00185 Rome, Italy \\ b “Istituto Pasteur-Fondazione Cenci Bolognetti”, Department of Chimica e Tecnologie del Farmaco, Sapienza University of Rome, P.le A. Moro, 5, I-00185 Rome, Italy \\ ${ }^{\mathrm{C}}$ Department of Public Health and Infectious Diseases, “Sapienza” University of Rome, Piazzale Aldo Moro 5, 00185 Rome, Italy
}

\section{A R T I C L E I N F O}

\section{Article history:}

Received 15 September 2016

Revised 29 October 2016

Accepted 31 October 2016

Available online $\mathrm{xxxx}$

\section{Keywords:}

Biofilm

Candida albicans

Cinnamic esters

Cinnamoyl amides

\begin{abstract}
A B S T R A C T
Some compounds, characterized by phenylethenyl moiety, such as methyl cinnamate and caffeic acid phenethyl ester, are able to inhibit $C$. albicans biofilm formation. On these bases, and as a consequence of our previous work, we synthesized a series of cinnamoyl ester and amide derivatives in order to evaluate them for the activity against $C$. albicans biofilm and planktonically grown cells.

The most active compounds $\mathbf{7}$ and $\mathbf{8}$ showed $\geqslant 50 \%$ biofilm inhibition concentrations $\left(\mathrm{BMIC}_{50}\right.$ ) of $2 \mu \mathrm{g} /$ $\mathrm{mL}$ and $4 \mu \mathrm{g} / \mathrm{mL}$ respectively, against $C$. albicans biofilm formation; otherwise, 7 showed an interesting activity also against mature biofilm, with BMIC $_{50}$ of $8 \mu \mathrm{g} / \mathrm{mL}$.
\end{abstract}

(c) 2016 Elsevier Ltd. All rights reserved.
Candida albicans (C. albicans) is the most common fungal pathogen in clinical settings and it is responsible of infections that can affect the skin and the mucosa or cause life-threatening systemic disease. ${ }^{1,2}$ The mortality among patients with invasive candidiasis is as higher than $40 \%$, even when patients receive antifungal therapy. ${ }^{3}$

One of the major problem related to the treatment of $C$. albicans infections is therapeutic failure, especially due to the onset of therapeutic resistance phenomena, which are very often associated with the biofilm formation. ${ }^{4}$

Biofilms are defined as complex microbial communities encased in a matrix of extracellular polymeric substances, that develops when a community of microorganisms irreversibly adheres to an inert or living surface. Contact with a solid surface triggers the expression of a panel of enzymes, which catalyze the formation of sticky polysaccharides that promote the surface colonization and the microbial cells protection. This adherent community is considered an important virulence factor because it is difficult to eradicate and often responsible for treatment failures. ${ }^{5}$ Indeed, the biofilm represents a physical barrier that prevents drugs from entering and expressing their activity.

\footnotetext{
* Corresponding author.

E-mail address: luigi.scipione@uniroma1.it (L. Scipione).

1 The authors Daniela De Vita and Giovanna Simonetti equally contributed to the work.
}

In C. albicans the morphogenesis and the biofilm formation are controlled by a complex mechanism of communication termed quorum sensing (QS), a process that is sensitive to the cell density in the biofilm population. The QS is based on the exchange and sensing of low molecular weight signal compounds, ${ }^{6}$ in particular, three substances have been identified as QS molecules: farnesol, phenylethyl alcohol and tryptophol. ${ }^{7}$ However, the antifungal resistance of $C$. albicans biofilm is complex and it involves not only the physical barrier due to the polysaccharide layer, but a number of different mechanisms, such as over-expression of efflux pumps, genetic changes of drug targets, persister cells, biofilm-host immune system interaction. ${ }^{8}$

Azoles currently used for the treatment of systemic infections (e.g. fluconazole, itraconazole) have little effect against Candida biofilms, even at high doses and in combination with caspofungin. ${ }^{9}$ For these reasons, new therapies are urgently needed to treat the wide variety of Candida biofilm infections in the medical setting.

In literature there are few compounds able to inhibit $C$. albicans biofilm formation, ${ }^{10}$ among them there are methyl cinnamate and caffeic acid phenethyl ester (CAPE), characterized by phenylethenyl moiety. ${ }^{11}$ Based on these evidences, in our previous work we tested, against $C$. albicans planktonic and biofilm cells, a series of caffeic and cinnamic acid derivatives (Chart 1).

By referring to the structure of CAPE and its biological properties, ${ }^{12-14}$ we synthesized several ester and amide compounds with simple chains or several more complex groups. Furthermore, we 
<smiles>COC(=O)/C=C/c1ccccc1</smiles>

Methyl cinnamate<smiles>O=C(O)/C=C/c1ccccc1</smiles>

Cinnamic acid<smiles>O=C(/C=C/c1ccc(O)c(O)c1)OCCc1ccccc1</smiles><smiles>O=C(O)/C=C/c1ccc(O)c(O)c1</smiles>

Caffeic acid<smiles>O=C(/C=C/c1ccccc1)OCc1ccc([N+](=O)[O-])o1</smiles>

Lead compound (1)

Chart 1. Compounds characterized by a phenylethenyl moiety and our lead compound 1.

have removed the two hydroxylic groups, typical of caffeic acid derivatives, saturated or removed the ethenyl double bond of the acylic moiety. As a result of that work, we identified a new cinnamate derivative ((5-nitrofuran-2-yl)methyl-(2E)-3-phenyl-

prop-2-enoate (1) showing a good inhibition activity against $C$. albicans biofilm. It was able to inhibit the biofilm formation and to reduce the metabolic activity of preformed biofilm, better than the reference drug fluconazole.

Our basic SAR study has showed that the conjugation of the carbonyl group with an unsaturated system seems to be relevant for the anti-biofilm activity; furthermore, the presence of the hydroxylic groups appears to be not necessary. ${ }^{15}$

In this paper we report the synthesis and the activity evaluation, on $C$. albicans biofilm, of a new series of cinnamoyl ester and amide derivatives that have been designed with the idea of preserving the cinnamoyl moiety and removing the hydroxyl groups of caffeic acid, in order to obtain an improved chemical stability and a simplified reaction work up.

We also investigated the importance of the nitro group, present in our reference compound (1), forasmuch as, it is known from the literature that compounds able to induce the production of reactive oxygen species (ROS) possess a potential antibiofilm activity. ${ }^{16,17}$ The ROS are usually generated by in vivo electron transfer processes that involve specific chemical functionalities including aromatic nitro compounds. ${ }^{18}$ In this context, we have synthesized several ester and amide derivatives combining the carboxylic function of cinnamic acid with different groups, including nitro heterocyclic groups, azole and indole rings (Chart 2).

We also synthesized some molecular hybrids between cinnamic acid and other compound endowed with own antifungal activity. In particular, we have chosen molecular fragment of anti-biofilm compounds as miconazole (7) and molecules that are active against planktonic cells as fluconazole $(\mathbf{8}){ }^{19}$<smiles>[R]C(=O)C=Cc1ccccc1</smiles>
Compound
$\mathbf{R}$
Compound
$\mathbf{R}$
1<smiles>COCc1ccc([N+](=O)[O-])o1</smiles>
6
2<smiles>COCCn1c([N+](=O)[O-])cnc1C</smiles>
7

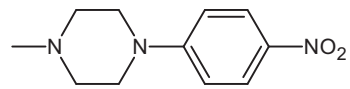
8<smiles>CN1CCN(c2ncccc2[N+](=O)[O-])CC1</smiles>
5<smiles>COCc1ccco1</smiles>
3
4<smiles>CNc1nc2ccc([N+](=O)[O-])cc2s1</smiles><smiles>COC(Cn1ccnc1)c1ccc(Cl)cc1Cl</smiles><smiles>COC(Cn1cncn1)(Cn1cncn1)c1ccc(F)cc1F</smiles>
9<smiles>CNCCCn1ccnc1</smiles><smiles>CNCCc1c[nH]c2ccccc12</smiles>

Chart 2. Studied cinnamic acid derivatives 1-10. 


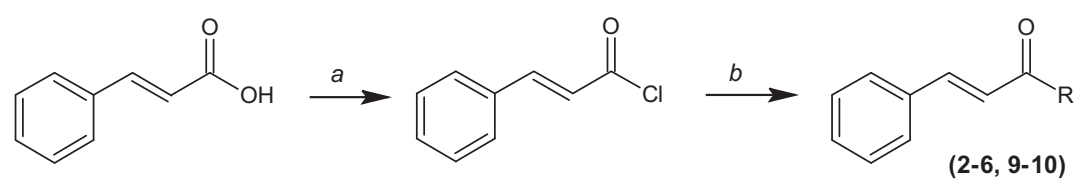

Scheme 1. General procedure for the synthesis of 2-6, 9-10. (a) $\mathrm{SOCl}_{2}, 2$ h, reflux; (b) opportune alcohol or amine, TEA, DCM, 12 h, reflux (2-6, 9) or r.t. (10).

Furthermore, we synthesized the derivative 10, a hybrid between cinnamic acid and tryptamine, because it is demonstrated that compounds, such as indole and 3-indolylacetonitrile, are able to reduce biofilm formation and virulence, by the regulation of NRG1, a transcriptional factor that influences filamentation and biofilm formation in C. albicans. $^{20}$

The synthetic procedures of the studied compounds are illustrated in the Schemes 1 and 2; briefly, the cinnamic acid was activated to cinnamoyl chloride by the treatment with $\mathrm{SOCl}_{2}$, then the opportune alcohol or amine were added to synthesize the corresponding ester $(\mathbf{2}, \mathbf{6})$ or amide $(\mathbf{3 - 5}, \mathbf{9}, \mathbf{1 0})$.

The compounds $\mathbf{2}, \mathbf{5}$ and $\mathbf{1 0}$ were synthesized modifying the procedures reported in literature. $^{21-23}$

For the synthesis of the compound 2, the metronidazole was obtained by extraction with dichloromethane after shattering commercial tablets in warm water ${ }^{24}$; whereas, the 1-(3-nitropyridin-2-yl)piperazine, necessary to synthesize compound $\mathbf{4}$, was prepared as we have previously reported. ${ }^{25}$

Attempts to synthesize esters $\mathbf{7}$ and $\mathbf{8}$ using the above illustrated scheme were unsuccessful, then it was necessary to preventively activate the alcoholic function by $\mathrm{NaH}$ before the reaction with cinnamoyl chloride.

The detailed synthetic procedures, the analytical and spectroscopic data of new synthesized compounds are reported in the supplementary material and are in agreement with the proposed structures.

Cinnamic acid, its derivatives $\mathbf{2 - 1 0}$ and parent alcohol or amine compounds, have been screened to evaluate the activity against planktonically growing $C$. albicans cells and against $C$. albicans biofilm formation and preformed. For the in vitro antifungal and antibiofilm experiments, described in detail in the supplementary material, C. albicans ATCC 10231 was used. This strain is sensitive to fluconazole on planktonic cells ( $\mathrm{MIC}_{50} 0.5 \mu \mathrm{g} / \mathrm{mL}$ ) and it is resistant in the different phases of biofilm formation (BMIC $_{50} 128 \mu \mathrm{g} /$ $\mathrm{mL}$ and $>128 \mu \mathrm{g} / \mathrm{mL}$ respectively on biofilm formation and mature biofilm). The minimal inhibitory concentration (MIC) was calculated and expressed as the lowest drug concentration at which a significant decrease in turbidity $(>50 \%)$ was detected in comparison with the control in the absence of drug. The $50 \%$ inhibitory concentration $\left(\mathrm{BMIC}_{50}\right.$ ) were defined as the concentrations causing $50 \%$ inhibition of either biofilm formation or preformed biofilms due to drug treatment.
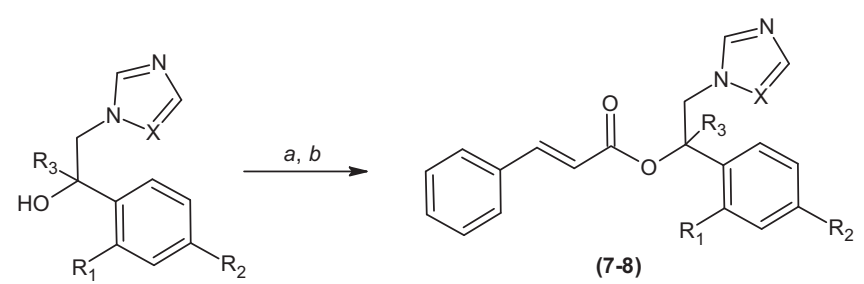

$$
\begin{aligned}
& \text { 7. } R_{1}=R_{2}=C l ; R_{3}=H ; X=C H \\
& \text { 8. } R_{1}=R_{2}=F ; R_{3}=1 H-1,2,4 \text {-triazole; } X=N
\end{aligned}
$$

Scheme 2. General procedure for the synthesis of 7, 8. (a) $\mathrm{NaH}, \mathrm{CH}_{3} \mathrm{CN}, 2$ h, r. t. (7) or $50{ }^{\circ} \mathrm{C}(\mathbf{8})$; (b) cinnamoyl chloride, 12 h, r. t. (7) or $50^{\circ} \mathrm{C}(8)$
The results of the microbiological assays are summarized in Table 1, where the $\mathrm{MIC}_{50}$ and $\mathrm{BMIC}_{50}$ values of the synthesized cinnamic derivatives $\mathbf{2 - 1 0}$ are compared to the earlier published compound 1, cinnamic acid and parent alcohol and amine compounds.

In most cases the presence of the cinnamic moiety produces an increase of the antibiofilm activity, particularly for the biofilm formation, as can be observed for compounds 2, 6, 7, 8 and 10 with respect of the corresponding amines or alcohols. The only exception is presented by the compound $\mathbf{5}$, for which was observed an increase of the $\mathrm{BMIC}_{50}$ values compared to the corresponding amine.

The activities of compounds $\mathbf{2 - 5}$ on mature biofilm, on biofilm formation, as well on planktonic cells, range from 32 to $>128 \mu \mathrm{g} / \mathrm{mL}$. These data indicate that the replacement of the nitrofuran moiety of the reference compound $\mathbf{1}$ with other nitroheterocyclic groups, as nitroimidazole (2), nitropyridine and (4) nitrobenzothiazole (5), or nitrophenyl group (3), resulted in a significant reduction of the antibiofilm activity. Furthermore, the removal of the nitro group from the compound $\mathbf{1}$ to obtain the furan derivative $\mathbf{6}$ did not produce significant changes against biofilm in formation but it reduced the activity on preformed biofilm, as the $\mathrm{BMIC}_{50}$ increased from 64 to $128 \mu \mathrm{g} / \mathrm{mL}$, and more markedly on planktonic cells, as the $\mathrm{MIC}_{50}$ increased from 2 to $64 \mu \mathrm{g} / \mathrm{mL}$.

Taken together, the activity data for compound 2-5 compared to $\mathbf{1}$ indicate that the presence of nitrofuran moiety appears to be critical to obtain the anti-biofilm activity. These data also suggest that the antibiofilm activity of the nitrofuran moiety could be due to a combined action on planktonic cells and on the biofilm, especially in the mature phases.

It is noteworthy that in this study we have identified other new interesting anti biofilm compounds. Cinnamic acid not showed antibiofilm activity, as reported in Table 1, but combining it with molecular fragments that are present in antifungal drugs, new compounds have been obtained with antibiofilm activities.

In particular, the most active derivative $\mathbf{7}$, containing a molecular fragment of miconazole, has shown inhibition of biofilm in formation at the concentration of $2 \mu \mathrm{g} / \mathrm{mL}$ and reduction in metabolic activity of preformed biofilm at $8 \mu \mathrm{g} / \mathrm{mL}$, lower than the lead compound 1 (16 and $64 \mu \mathrm{g} / \mathrm{mL}$, respectively) and the reference drug fluconazole (128 and $>128 \mu \mathrm{g} / \mathrm{mL}$, respectively).

Finally, the esterification of fluconazole with cinnamic acid, to produce the hybrid compound (8), it has led to a significant increase in the activity on biofilm formation (BMIC ${ }_{50} 4 \mu \mathrm{g} / \mathrm{mL}$ vs $128 \mu \mathrm{g} / \mathrm{mL}$ ) and in minor extent on preformed biofilm. On the other hand, the hybrid of cinnamic acid with tryptamine (10) have produced an enhancement of the anti-biofilm activity, selectively against biofilm in formation, with the reduction of BMIC $_{50}$ value from $128 \mu \mathrm{g} / \mathrm{mL}$ to $8 \mu \mathrm{g} / \mathrm{mL}$.

In conclusion, the synthesis of amide and ester derivatives of cinnamic acid has allowed to identify new compounds endowed of antibiofilm activity, particularly effective in the early phases of biofilm formation. The cinnamic moiety does not seem to act as a simple lipophilic carrier but instead appears to be responsible for antibiofilm activities; in fact, in most cases, quite active esters or amides were obtained from amines or alcohols which do not have activity on biofilm (compounds 1, 2, 3 and 6 vs parent alcohols or amides). Furthermore, the cinnamic group enhances 
Table 1

Antifungal activity of compounds 1-10, cinnamic acid and the parent compounds against C. albicans ATCC 10231 biofilm and planktonic cells.

\begin{tabular}{|c|c|c|c|c|}
\hline \multirow[t]{2}{*}{ Ester or amide compound } & \multicolumn{2}{|c|}{$\mathrm{BMIC}_{50}(\mu \mathrm{g} / \mathrm{mL})$} & \multirow{2}{*}{$\begin{array}{l}\mathrm{MIC}_{50}(\mu \mathrm{g} / \mathrm{mL}) \\
\text { Planktonic cells }\end{array}$} & \multirow[t]{2}{*}{ Parent alcohol or amine } \\
\hline & Mature biofilm & Biofilm formation & & \\
\hline \multirow[t]{2}{*}{1} & 64 & 16 & 2 & \\
\hline & 64 & 64 & 16 & \\
\hline \multirow[t]{2}{*}{2} & $>128$ & 32 & 128 & \\
\hline & $>128$ & $>128$ & $>128$ & $\mathrm{NO}_{2}$ \\
\hline \multirow[t]{2}{*}{3} & $>32$ & $>128$ & 32 & \\
\hline & $>128$ & $>128$ & $>128$ & \\
\hline \multirow[t]{2}{*}{4} & $>128$ & $>128$ & $>128$ & \\
\hline & $>128$ & $>128$ & $>128$ & \\
\hline \multirow[t]{2}{*}{5} & $>128$ & $>128$ & $>128$ & \\
\hline & 64 & 64 & $>128$ & \\
\hline \multirow[t]{2}{*}{6} & 128 & 16 & 64 & \\
\hline & $>128$ & $>128$ & $>128$ & \\
\hline \multirow[t]{2}{*}{7} & 8 & 2 & 2 & \\
\hline & 64 & 64 & 16 & \\
\hline \multirow[t]{2}{*}{8} & $>32$ & 4 & 64 & \\
\hline & $>128$ & 128 & 0.5 & \\
\hline \multirow[t]{2}{*}{9} & $>128$ & $>128$ & $>128$ & \\
\hline & $>128$ & $>128$ & $>128$ & $\mathrm{H}_{2} \mathrm{~N}$ \\
\hline \multirow[t]{2}{*}{10} & $>128$ & 8 & $>128$ & \\
\hline & $>128$ & 128 & $>128$ & \\
\hline Cinnamic acid & $>128$ & $>128$ & $>128$ & \\
\hline
\end{tabular}

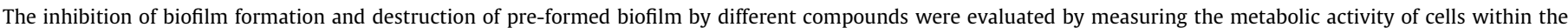

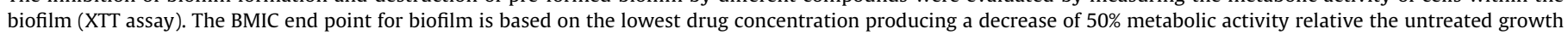

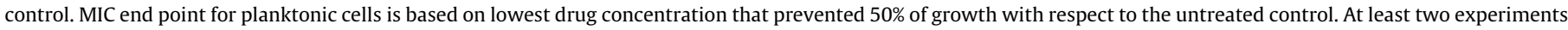
were performed on two separate dates for each compound tested in triplicate. The results were expressed as median.

the weak antibiofilm activity of the 1-(2,5-dichlorophenyl)-2-(1Himidazol-1-yl)ethanol, the parent alcohol of ester 7, and confers good antibiofilm activity to fluconazole, the parent alcohol of ester 8.

The activity data obtained for these cinnamic derivatives also indicate that the approach of combining into a hybrid, two molecular fragments characterized by their own activities, could be advantageously exploited to develop new compounds with antibiofilm activity.

\section{Acknowledgement}

This work was supported by "Progetto di Ateneo 2014" funding from Sapienza University of Rome. 


\section{A. Supplementary data}

Supplementary data associated with this article can be found, in the online version, at http://dx.doi.org/10.1016/j.bmcl.2016.10. 091. These data include MOL files and InChiKeys of the most important compounds described in this article.

\section{References}

1. Samaranayake, L. P. Dent. Update $1990,17,36$

2. van de Veerdonk FL, Kullberg BJ, Netea MG. Curr Opin Crit Care. 2010;16:453.

3. Kullberg BJ, Arendrup MC. N Engl J Med. 2015;373:1445.

4. Blankenship JR, Mitchell AP. Curr Opin Microbiol. 2006;9:588.

5. Kumamoto CA. Curr Opin Microbiol. 2002;5:608.

6. De Sordi L, Mühlschlegel FA. FEMS Yeast Res. 2009;9:990.

7. Kruppa M. Mycoses. 2009;52:1.

8. Borghi E, Borgo F, Morace G. In: Imbert C, editor. Advances in Experimental Medicine and Biology, Vol. 931. Switzerland: Springer International Publishing: 2016:37-47.
9. Bouza E, Guinea J, Guembe M. Antibiotics. 2015;4:1

10. Stiz D, Corrêa R, D’Auria FD, et al. Med Chem. 2016;12. http://dx.doi.org/ 10.2174/1573406412666160229150833.

11. Breger J, Fuchs BB, Aperis G, et al. PLoS Pathog. 2007;3:168.

12. Sanderson JT, Clabault H, Patton C, et al. Bioorg Med Chem. 2013;21:7182.

13. LeBlanc LM, Paré AF, Jean-François J, et al. Molecules. 2012;17:14637.

14. Beauregard A, Harquail J, Lassalle-Claux G, et al. Molecules. 2015;20:12576.

15. De Vita D, Friggeri L, D’Auria FD, et al. Bioorg Med Chem Lett. 2014;24:1502.

16. Delattin N, Cammue BPA, Thevissen K. Future Med Chem. 2014;6(1):77.

17. De Cremer K, De Brucker K, Staes I, et al. Sci Rep. 2016;6:27463.

18. Kovacic P, Becvar LE. Curr Pharm Design. 2000;6(2):143.

19. Vandenbosch D, Braeckmans K, Nelis HJ, et al. J Antimicrob Chemother. 2010;65:694.

20. Oh S, Go GW, Mylonakis E, et al. J Appl Microbiol. 2012;113:622.

21. Yong Q, Hong-Jia Z, Hao Z, et al. Bioorg Med Chem. 2010;18:4991.

22. Amnerkar ND, Bhusari KP. Eur J Med Chem. 2010;45:149.

23. Kiviranta PH, Salo HS, Leppänen J, et al. Bioorg Med Chem. 2008;16:8054.

24. Piccaro G, Filippini P, Giannoni F, et al. J Chemother. 2011;23:175.

25. Moraca F, De Vita D, Pandolfi F, et al. Eur J Med Chem. 2014;83:665. 